\title{
In situ Formation of Nano Ni-Co Oxyhydroxide Enables Water Oxidation 1 Electrocatalysts Durable at High Current Densities
}

\author{
Jehad Abed, Shideh Ahmadi, Laura Laverdure, Ahmed Abdellah, Colin P. O’Brien, \\ Kevin Cole, Pedro Sobrino, David Sinton, Drew Higgins, Nicholas J Mosey, Steven J. \\ Thorpe, and Edward H. Sargent
}

Version Post-print/accepted manuscript

Citation Abed, J., Ahmadi, S., Laverdure, L., Abdellah, A., O'Brien, C. P., Cole, (published version) K., Sobrinho, P., Sinton, D., Higgins, D., Mosey, N. J., Thorpe, S. J., Sargent, E. H., In Situ Formation of Nano Ni-Co Oxyhydroxide Enables Water Oxidation Electrocatalysts Durable at High Current Densities. Adv. Mater. 2021, 33, 2103812.

Publisher's Statement This is the peer reviewed version of the following article: Abed, J., Ahmadi, S., Laverdure, L., Abdellah, A., O'Brien, C. P., Cole, K., Sobrinho, P., Sinton, D., Higgins, D., Mosey, N. J., Thorpe, S. J., Sargent, E. H., In Situ Formation of Nano Ni-Co Oxyhydroxide Enables Water Oxidation Electrocatalysts Durable at High Current Densities. Adv. Mater. 2021, 33, 2103812. which has been published in final form at https://doi.org/10.1002/adma.202103812 This article may be used for non-commercial purposes in accordance with Wiley Terms and Conditions for Use of Self-Archived Versions.

\section{How to cite TSpace items}

\begin{abstract}
Always cite the published version, so the author(s) will receive recognition through services that track citation counts, e.g. Scopus. If you need to cite the page number of the author manuscript from TSpace because you cannot access the published version, then cite the TSpace version in addition to the published version using the permanent URI (handle) found on the record page.
\end{abstract}

This article was made openly accessible by $U$ of $T$ Faculty. Please tell us how this access benefits you. Your story matters. 


\section{In situ Formation of Nano Ni-Co Oxyhydroxide Enables Water Oxidation Electrocatalysts Durable at High Current Densities}

Jehad Abed ${ }^{1,2}$, Shideh Ahmadi ${ }^{3}$, Laura Laverdure ${ }^{3}$, Ahmed Abdellah ${ }^{4}$, Colin P. O’Brien ${ }^{5}$, Kevin Cole ${ }^{1}$, Pedro Sobrino ${ }^{1}$, David Sinton ${ }^{5}$, Drew Higgins ${ }^{4}$, Nicholas J Mosey ${ }^{3}$, Steven J. Thorpe $^{1 *}$, and Edward H. Sargent ${ }^{2 *}$

${ }^{1}$ Department of Materials Science and Engineering, University of Toronto, 184 College

Street, Toronto, Ontario M5S 3E4, Canada.

${ }^{2}$ Department of Electrical and Computer Engineering, University of Toronto, 35 St George Street, Toronto, Ontario M5S 1A4, Canada.

${ }^{3}$ Department of Chemistry, Queen's University, Kingston, Ontario, Canada.

${ }^{4}$ Department of Chemical Engineering, McMaster University, Hamilton, Ontario, Canada.

${ }^{5}$ Department of Mechanical and Industrial Engineering, University of Toronto, 5 King's

College Road, Toronto, ON M5S 3G8, Canada.

*Correspondence and requests for materials should be addressed to Edward Sargent (ted.sargent@utoronto.ca) and Steven Thorpe(steven.thorpe@utoronto.ca)

Abstract. The oxygen evolution reaction (OER) limits the energy efficiency of electrocatalytic systems due to the high overpotential symptomatic of poor reaction kinetics; this problem worsens over time if the performance of the OER electrocatalyst diminishes during operation. Here we report a novel synthesis of nanocrystalline Ni-Co-Se for alkaline OER using ball milling at cryogenic temperature. We discovered that, by anodizing the Ni-Co-Se structure during OER, Se ions leached out of the original structure completely, allowing water molecules to hydrate $\mathrm{Ni}$ and Co defective sites, and the nanoparticles to evolve into an active Ni-Co oxyhydroxide. We observe this transformation using operando synchrotron x-ray absorption spectroscopy, with the findings confirmed using density functional theory calculations. The 
resulting electrocatalyst exhibited an overpotential of $279 \mathrm{mV}$ at $0.5 \mathrm{~A} . \mathrm{cm}^{-2}$ and $329 \mathrm{mV}$ at 1

27 A.cm ${ }^{-2}$ and sustained performance for 500 hours. This is achieved using low mass loadings

\subsection{Introduction}

With the large anticipated penetration of low-cost renewable electricity into the power grid comes the need for cost-effective decarbonization strategies combined with large-scale storage. Water splitting and $\mathrm{CO}_{2}$ reduction $\left(\mathrm{CO}_{2} \mathrm{R}\right)$ can store electricity in the form of stable chemical bonds in synthetic fuel and chemical feedstocks, mitigating the variability challenge of renewable energy. ${ }^{[1-3]}$ However, the efficiency of these electrocatalytic systems is limited by the sluggish kinetics and high overpotentials at the anode imposed by the oxygen evolution reaction (OER) ${ }^{[4]}$ A relatively small selection of OER electrocatalysts meets the requirements needed for industrial electrocatalysis; low OER overpotentials $(<300 \mathrm{mV})$ at high current densities $\left(>500 \mathrm{~mA} \cdot \mathrm{cm}^{-2} \text { ) for long-term operation (ultimately }>60,000 \mathrm{~h}\right)^{[5]}$. Identifying durable and efficient OER electrocatalysts is urgently needed to enable large-scale industrial implementation of important electrocatalytic technologies such as water splitting and $\mathrm{CO}_{2} \mathrm{R}$.

To date, benchmark noble electrocatalysts based on $\mathrm{RuO}_{\mathrm{x}}$ and $\mathrm{IrO}_{\mathrm{x}}$ are considered stateof-the-art OER electrocatalysts in view of their superior performance; unfortunately, their high price and scarcity limit their widespread application. In contrast, earth abundant metal oxides, selenides, nitrides and phosphides derived from the first-row transition metals $\mathrm{Ni}, \mathrm{Co}$, and $\mathrm{Fe}$ can offer a cheaper alternative for efficient OER electrocatalysts in anion exchange membrane 
50

(AEM) systems, which utilize an alkaline environment that is more compatible with non-noble metal electrocatalysts than an acidic environment.

One of the most efficient non-noble OER electrocatalysts in alkaline systems is Fe doped NiOOH. ${ }^{[6-8]}$ While a small amount of Fe can boost the OER electrocatalytic activity of $\mathrm{NiOOH}$, it has been reported that, Fe segregates from the Ni-Fe oxyhydroxide lattice to form a secondary $\mathrm{FeOOH}$ phase that deactivates the electrocatalyst. ${ }^{[9]}$ Berlinguette et al. found that at $200 \mathrm{~mA} \cdot \mathrm{cm}^{-2}$ in strong base electrolytes, $\mathrm{NiFeO}_{\mathrm{x}}$ OER electrocatalyst had a similar degradation problem as a significant amount of Fe left the structure and diffused to the cathode $^{[10]}$ Furthermore, Markovic et al. investigated the activity and stability trends for monometallic oxyhydroxides and observed that $\mathrm{Fe}$ is the least stable compared to $\mathrm{Ni}$ and $\mathrm{Co} .{ }^{[11]}$ These findings motivate the development of an Fe-free earth abundant OER electrocatalyst that is both active and stable in alkaline conditions.

Among candidates to replace $\mathrm{Fe}$ in Ni electrocatalysts, Co is known to lower the OER overpotential and improve electrochemical stability. ${ }^{[12,13]}$ However, since Co is heavily used in energy applications, especially Li-ion batteries, it is anticipated that that it may suffer supply shortages in future. ${ }^{[14]}$ This mandates the development of methods to reduce Co loadings in energy materials. Here we deploy Se, a chalcogenide, with $\mathrm{Ni}$ and $\mathrm{Co}$, to serve as a sacrificial scaffold to enable the efficient activation of small mass loadings of Co in the electrocatalyst during OER. Prior reports have shown that metal selenides are thermodynamically unstable during OER at high $\mathrm{pH}$, resulting in structural changes such as increased nanoporosity, disordering in the lattice, and high density of defective surface sites. ${ }^{[15-17]}$ We lever these localized structural changes to form, in situ amorphous nano Ni-Co oxyhydroxides with high mass and specific activities.

Synthesizing metal chalcogenides has previously proven challenging due to the immiscibility of the constituent elements and the need for high thermal activation temperatures 
$>500{ }^{\circ} \mathrm{C}$. ${ }^{[18]}$ We used cryomilling - ball milling at cryogenic temperatures - to synthesize well-mixed Ni-Co-Se electrocatalysts. Milling at such low temperatures provided us with control over a wide compositional range of the compound and enabled the formation of amorphous structures. Amorphous metals have been produced by a variety of methods: atomization, electrodeposition, electroless deposition, planar and flow casting. However, amorphous alloys produced by these methods are limited to a narrow compositional range near low melting point eutectics, unlike cryomilling which can produce a wider range of amorphous phases centered around high melting point intermetallics. Accordingly, targeting Ni-Co-Se compositions with a high melting point favors disordering and the formation of abundant defective and coordinatively unsaturated sites (CUS) that can facilitate the hydration of Ni and Co sites and the formation of oxyhydroxides. ${ }^{[12,16,19-22]}$ After synthesis, we activated Ni-CoSe by subjecting it to OER conditions and evaluating its half-cell activity and stability at high current densities $>100 \mathrm{~mA} \cdot \mathrm{cm}^{-2}$. The activation process was investigated using operando Xray absorption spectroscopy (XAS), electron energy-loss spectroscopy (EELS), and density functional theory (DFT) calculations. We find that Se leaches, induces surface reconstruction during OER, and facilitates the hydration of metal centers to form active oxyhydroxides. We study the performance of $\mathrm{Ni}-\mathrm{Co}-\mathrm{Se}$ as OER electrocatalyst with respect to requirements for water splitting and $\mathrm{CO}_{2} \mathrm{R}$ in a $5 \mathrm{~cm}^{2}$ AEM-based membrane-electrode-assembly (MEA) electrolyzer. We report a full cell voltage delivering $1 \mathrm{~A} . \mathrm{cm}^{-2}$ at $1.75 \mathrm{~V}$ for water splitting and $3 \mathrm{~V}$ for $\mathrm{CO}_{2} \mathrm{R}$.

\subsection{Synthesis and activation of electrocatalysts.}

The electrocatalysts were synthesized using a one-pot ball milling process in two steps 1) mechanical alloying at a cryogenic temperature $\left(<-196^{\circ} \mathrm{C}\right)$ to produce disordered structures and 2) surfactant-assisted ball milling (SABM) at room temperature to reduce the size of the alloy to nanoparticles (Figure 1a). The combination of high-speed mixing (30 Hz, $1800 \mathrm{rpm}$ ) 
and low temperature $\left(-196^{\circ} \mathrm{C}\right)$ facilitates the formation of nanocrystalline structures centered at high-melting point compositions (see supplementary information for synthesis description).

First, Ni-Se and Co-Se control samples were synthesized to investigate the milling behaviour of $\mathrm{Ni}$ and $\mathrm{Co}$ with $\mathrm{Se}$ and to confirm the formation of metal selenide phases without the need for thermal activation. We observed characteristic XRD peaks of binary metal selenide phases after just 6 hours of cryomilling and no peaks for elemental $\mathrm{Ni}, \mathrm{Co}$, or Se, indicative of full incorporation of Se in a mixed Ni-Co selenide structure (Figures S1 and S2). Due to the high kinetic energy induced by ball-powder-ball collisions at high speeds, alloying is facilitated by repeated fracture and cold welding of the particles, while crystal defects and the local rise in temperature aids the diffusion of elements in the alloyed structure. ${ }^{[23]} \mathrm{We}$ found that, despite the possibility of particles welding together due to excessive collisions during milling, Se played an important role in stabilizing single phase nanoparticles $(<100 \mathrm{~nm})$ with $\mathrm{Ni}$ and $\mathrm{Co}$ (see supplementary information). To reduce Fe contamination from the stainless steel balls and the walls of the vial during milling, we run the mill for a few minutes with the starting precursors to cover all the inside walls of the vial and the surface of the balls with a thick layer of the precursor and prevent direct collision with any Fe. Using inductive coupling plasma atomic emission spectroscopy ICP-AES, we found that the Fe concentration in the catalyst after cryomilling was limited to $0.05 \pm 0.03$ at. \% (see supplementary information for experimental details).

Afterwards, we synthesized Ni-Co-Se compounds centered about two high-melting point compositions: $(\mathrm{NiCo}) \mathrm{Se}$ and $\left(\mathrm{NiCo}_{3} \mathrm{Se}_{4}\right.$. The particles of $\mathrm{Ni}-\mathrm{Co}-\mathrm{Se}$ compounds had an average size greater than $1 \mu \mathrm{m}$ and a small surface-to-volume ratio, which is undesirable for electrocatalysis. Therefore, a surfactant was used in the second SABM step to reduce the particle size of the alloyed compounds to $67 \mathrm{~nm}$ for $\left(\mathrm{NiCo}_{3} \mathrm{Se}_{4}\right.$ and $37 \mathrm{~nm}$ for $(\mathrm{NiCo}) \mathrm{Se}$

(Figures 1c, S4, S5, and S6). The broad diffraction peaks in XRD indicated that nano-sized 
125 crystallites $(8.37 \mathrm{~nm})$ were produced after SABM (Figure 1b, see supplementary for 126 calculations). Finally, the surfactant was removed from the surface of the alloy after synthesis 127 via washing. After milling, the particles were sonicated for 30 mins in ethanol before 128 centrifuging at $10,000 \mathrm{rpm}(11,000 \mathrm{rcf})$ for $1 \mathrm{~h}$ and then the clear solution was washed and 129 replaced with fresh ethanol: this procedure was repeated three times until the nanoparticles 130 precipitated to the bottom of the tube. Thermogravimetric analysis (TGA) was conducted to evaluate the extent of removal of the surfactant species after washing. The uncleaned sample had $\sim 2$ wt. \% mass loss attributed to the residual surfactant, whereas there was a negligible mass loss $(<0.001 \mathrm{wt} . \%$, below the detection limit of the instrument) for the washed particles, 134 indicating the washing step was effective in removing the surfactant (Figure S7). In summary, 135 Se played an important role in tailoring the size and crystal structure of the cryomilled alloys. 136 Cryomilling Ni-Co without Se produces large $(>6 \mu \mathrm{m})$ crystalline particles which are not amorphized even under prolonged milling times (Figure S3).

We then activated ( $\mathrm{NiCo}) \mathrm{Se}$ and $(\mathrm{NiCo})_{3} \mathrm{Se}_{4}$ electrochemically by selectively leaching

139 Se out of the nanocrystalline structure (Figure 2a). According to the Pourbaix diagram of Se,

140 Se oxidizes to soluble $\mathrm{SeO}_{3}{ }^{2-} / \mathrm{SeO}_{4}{ }^{2-}$ at high $\mathrm{pH}$ during the OER. The activation process was conducted in $1 \mathrm{M}$ of pre-electrolyzed $\mathrm{KOH}$, to purify the electrolyte from $\mathrm{Fe}$ ions that could

142 participate in the reaction (Figure S8), and initiated by applying a constant current density of $14310 \mathrm{~mA} \cdot \mathrm{cm}_{\mathrm{geo}}{ }^{-2}$ in a three-electrode cell for 2 hours, a sufficient time to warrant a complete 144 removal of Se. ${ }^{[15]}$

145 Scanning electron microscopy (SEM) images were taken for the as-synthesized $146\left(\mathrm{NiCo}_{3} \mathrm{Se}_{4}\right.$ samples before and after activation (Figure 2b). Clusters of nanoparticles were 147 observed in the as-synthesized sample and Se accounted for 56 at. \% in the structure. After 148 activation, the morphology of the clusters was altered and Se was completely removed (0 at. $149 \%$, as confirmed by energy dispersive spectroscopy (EDS)), while the atomic ratio between Ni 
and Co remained unchanged (1:1). TEM and electron energy loss spectroscopy (EELS)

151

152

153

154

155

156

157

158

159

160

161

162

163

164

165

166

167

168

169

170

171

172

173

174 mapping were conducted on the as-synthesized (Figure 2c) and activated samples (Figure 2d). EELS elemental maps showed that $\mathrm{Ni}, \mathrm{Co}$, and $\mathrm{Se}$ in the as-synthesized $(\mathrm{NiCo})_{3} \mathrm{Se}_{4}$ were homogeneously distributed in $c a .10 \mathrm{~nm}$ nanoparticles. This was also seen by scanning transmission electron microscopy (STEM) and EDS (Figure S6). EELS spectra were acquired from the areas indicated in the elemental maps (Figure S9). Using EELS L2,3 edge position, the oxidation state of $\mathrm{Ni}$ and $\mathrm{Co}$ in the as-synthesized sample was determined to be $2+$ (Figures S10a and S10b), this, in addition to the lack of $O$ signal inside the particles as shown by the $O$ EELS map (Figures 2d, S9a), confirmed that Ni and Co were incorporated in the selenide structure forming Ni-Co-Se. After activation, Se was not detected in the catalyst structure using EELS (Figures 2c, S10c), confirming that Se was completely leached out of the structure during electrochemical activation while $\mathrm{O}$ was present throughout the particles. The EELS L2,3 edge position of $\mathrm{Ni}$ and $\mathrm{Co}$ showed that the oxidation state of both $\mathrm{Ni}$ and Co were increased to $3+$ after activation (Figures S10a and S10b). Furthermore, we conducted inductively coupled plasma atomic emission spectroscopy (ICP-AES) on the catalyst during the first 48 hours of the OER (Figure S11). We observed that Se dissolved within the first ca. 10 mins of the OER confirming EELS and EDS observations. On the other hand, both Ni and Co remained intact in the catalyst as the total ions dissolved amounts were below the background equivalent concentrations (BEC) for Ni (17 ppb) and Co (12 ppb), respectively. XRD and electron diffraction pattern (DP) using TEM were collected after the activation of the sample to investigate the changes in the crystal structure of the catalyst. Both techniques confirmed the change in crystal structure during activation as indicated by the amorphous rings in DP and the

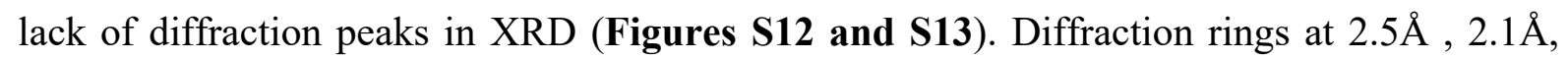
$1.5 \AA$ were clearly observed, corresponding to the (111), (100) and (110) crystal planes of $\mathrm{CoO} / \mathrm{Co}(\mathrm{OH})_{2}$, Carbon, and $\mathrm{Ni}(\mathrm{OH})_{2}$, respectively. ${ }^{[24,25]}$ 

conducted to investigate the local chemical and electronic changes to individual $\mathrm{Ni}, \mathrm{Co}$ and $\mathrm{Se}$ atoms after activation. Using a silicon drift detector (SDD), the X-ray absorption near edge structure (XANES) of Se L-edge was obtained. This revealed that Se was incorporated in the 179 dry nanoparticles as selenide $\left(\mathrm{Se}^{2-}\right)$, and that it departed the structure after activation as indicated by the lack of the Se L-edge signal after $2 \mathrm{~h}$ of OER (Figure 2e). ${ }^{[26]}$ The oxidation states of $\mathrm{Ni}$ and Co were inspected after activation as shown in XANES of $\mathrm{L}_{3}$-edge results (Figures 2f and 2g). Two different modes of X-ray detection were used to investigate the oxidation state: fluorescence X-rays using SDD and total electron yield (TEY). The TEY mode is dependent on the conductivity of the surface but is more surface sensitive $(<10 \mathrm{~nm})$ compared to SDD (within $100 \mathrm{~nm}$ ). Using both detection modes allowed us to investigate the changes in oxidation state within the bulk and on the surface of the electrocatalysts before and after activation. The XANES of $\mathrm{Ni}_{2}$-edge of the dry sample revealed that $\mathrm{Ni}$ had an oxidation state of $2+$ before activation while Co in the as-synthesized sample had a mixed oxidation state of $2+/ 3+$ on the surface implying that Co was in a spinel structure. ${ }^{[27]}$ The oxidation state of $\mathrm{Ni}$ and $\mathrm{Co}$ increased to $3+$ after activation possibly suggesting the transformation to NiCoOOH. ${ }^{[28,29]}$ Therefore, we will start describing the catalysts after activation in the following sections as "activated" to reflect the nature of the final structure which is $\mathrm{NiCoOOH}$.

\section{Electrocatalytic performance and stability}

The performance of catalysts after activation was evaluated by measuring the overpotential at $10 \mathrm{~mA} \cdot \mathrm{cm}_{\mathrm{geo}}{ }^{-2}$ on a glassy carbon electrode as in (Figure 3a). The activity of activated $(\mathrm{NiCo}) \mathrm{Se}$ and $(\mathrm{NiCo})_{3} \mathrm{Se}_{4}$ after $\mathrm{SABM}(\mathrm{NiCoOOH})$ improved dramatically due to an increase in the surface-to-volume ratio of the nanoparticles. Alloying $\mathrm{Ni}$ and $\mathrm{Co}$ in the electrocatalyst lowered the overpotential compared to binary NiSe and CoSe alone by $c a$. 50 $\mathrm{mV}$ confirming that $\mathrm{Ni}$ and Co have synergistic effects when alloyed together. ${ }^{[12,30]}$ The best 
performance was seen for activated $(\mathrm{NiCo})_{3} \mathrm{Se}_{4}(\mathrm{NiCoOOH})$ after $\mathrm{SABM}$ with an overpotential of $268 \pm 2 \mathrm{mV}$ at $10 \mathrm{~mA} \cdot \mathrm{cm}_{\text {geo }^{-2}}$ and a Tafel slope of $42 \mathrm{mV} \cdot \mathrm{dec}^{-1}$ (Figures S14 and S15 and Table S4).

To examine the specific catalytic activity, we normalized the current density by the electrochemical surface area (ECSA) using double-layer capacitance measured by cyclic voltammetry (CV) (Figures S16 and S17). Activated $\left(\mathrm{NiCo}_{3} \mathrm{Se}_{4}(\mathrm{NiCoOOH})\right.$ demonstrated ECSA current densities 4 times higher than commercial $\mathrm{IrO}_{2}$ using the same catalyst loading of $0.21 \mathrm{mg} . \mathrm{cm}^{-2}$ for all electrocatalysts (Figure 3b). The turnover frequency (TOF) of the catalyst was calculated as $50.76 \times 10^{-3} \mathrm{~s}^{-1}$ per site, considering only $\mathrm{Ni}$ and Co as active sites, ca. two folds higher than $\mathrm{IrO}_{2} 28.09 \times 10^{-3}$ per site implying activated $(\mathrm{NiCo})_{3} \mathrm{Se}_{4}(\mathrm{NiCoOOH})$ is intrinsically more active.

We then investigated the stability of the catalyst using chronopotentiometry at 10 mA.cmgeo ${ }^{-2}$ (Figure S18) . The catalyst maintained a steady overpotential value of $267 \mathrm{mV}$ for $100 \mathrm{~h}$ with only $4 \mathrm{mV}$ overpotential increase. At higher current densities and prolonged testing conditions, excessive oxygen bubbling can artificially increase the overpotential by shielding the active sites on the surface and within the pores of the electrocatalyst. Rotating disk electrodes (RDEs) are often used to overcome this problem and improve the detachment of bubbles from the surface of the electrocatalyst and lower mass transport limitations by rotation. However, vigorous rotation for long duration has been reported to affect the binding of the electrocatalyst to the surface of the RDE implying fallacious conclusions about the intrinsic stability of the electrocatalyst. ${ }^{[31]}$ Therefore, we proposed an alternating current test (ACT) to better assess the intrinsic stability of the electrocatalyst by removing bubbles without mechanical rotation. In ACT, a constant current density of $10 \mathrm{~mA} \cdot \mathrm{cmgeo}^{-2}$ was applied to the catalyst for $10 \mathrm{~h}$ and then it was allowed to rest at open circuit potential (OCP) for $1 \mathrm{~h}$ to release 
225 (LSV); this resembles one cycle of testing (Figure 3c). The potential slowly increased during the first few hours of each cycle because of bubble accumulation on the surface, however, the

227 initial potential was retained in the following cycle suggesting that bubbles were partially or completely released. The test was repeated for 34 cycles ( 340 hours of operation). After each cycle, the overpotential and Tafel slope were extracted and plotted with respect to time (Figure 3d). The electrocatalyst experienced a marginal increase in overpotential $(<10 \mathrm{mV})$ during the entire test while the Tafel slope remained unchanged suggesting that the reaction mechanism was not altered.

The performance of catalyst on nickel foam (NF) was tested at high current densities,

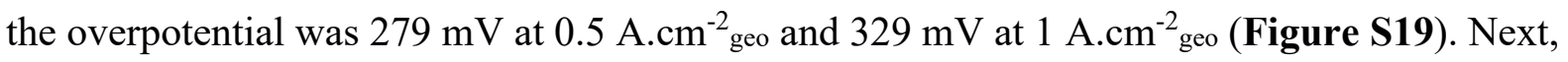
the stability of the electrocatalyst was evaluated under constant current density (Figure 3e). The electrocatalyst had an average potential increase of $0.17 \mathrm{mV} \cdot \mathrm{h}^{-1}$ in 500 hours. We compared the performance of activated $\left(\mathrm{NiCo}_{3} \mathrm{Se}_{4}(\mathrm{NiCoOOH})\right.$ with the electrocatalysts from the literature which had demonstrated a durable performance at high current densities $>100$ mA.cmgeo ${ }^{-2}$ (Table S5). Our catalyst had the highest mass actives A.gmetal ${ }^{-1}$ at 1 A.cm ${ }^{-2}$.

\section{Electronic structure}

To investigate the active species during OER and study the dynamics of the electrochemical activation of $(\mathrm{NiCo})_{3} \mathrm{Se}_{4}$, in situ XAS on the $\mathrm{K}$-edge of $\mathrm{Ni}$, Co and Se were conducted on the sample at four conditions: dry, OCP, at $1.1 \mathrm{~V}$ vs RHE, and during OER at $1.5 \mathrm{~V}$ vs RHE (Figure 4). XANES showed that $\mathrm{Se}$, in the dry sample, was present as a selenide $\left(\mathrm{Se}^{2-}\right)$ (Figure 4a) while $\mathrm{Ni}$ had an oxidation state of $2+$ and $\mathrm{Co}$ had a mixed oxidation state of $2+/ 3+$ suggesting that it exists in a spinel structure (Figures $4 \mathbf{b}$ and $4 \mathbf{c}$ ), confirming EELS and sXAS findings. ${ }^{[32-34]}$ During OER, Se was oxidized to Se (VI) at $1.5 \mathrm{~V}$ as evident by the positive energy shift of the peak at $12,666 \mathrm{eV}$ while the edge position of $\mathrm{Ni}$ and $\mathrm{Co}$ continuously increased to higher energy values indicating an increase in oxidation state to $3+$ 
during OER. ${ }^{[35]}$ Extended X-ray absorption fine structure (EXAFS) was conducted to

251

252

253

254

255

256

257

258

259

260

261

262

263

264

265

266

267

268

269

270

271

272

273

274 investigate the local structure changes in the vicinity of $\mathrm{Ni}, \mathrm{Co}$, and $\mathrm{Se}$ atomic sites during OER (Figures 4d, 4e, and 4f). A progressive increase in the Se-O peak at $1.7 \AA$ after OCP was observed confirming that $\mathrm{Se}$ was leaching out electrochemically as $\mathrm{SeO}_{4}{ }^{2-}$. In the case of $\mathrm{Ni}$ and Co, the as-synthesized sample showed a broad peak centered around ca. $2.3 \AA$ and $2.5 \AA$ for $\mathrm{Ni}$ and $\mathrm{Co}$, respectively, which corresponds to the single scattering path $\mathrm{Ni}-\mathrm{Se}$ and $\mathrm{Co}-\mathrm{Se}$ confirming the local formation of Ni-Co-Se. A FEFF EXAFS fitting was performed to determine the coordination of $\mathrm{Ni}$ and $\mathrm{Co}$ after cryomilling (Figure S20). The coordination of Ni was 3.5 and Co was 3.77 (Table S6). Both values are lower than the coordination number of non-defective atoms in tetrahedral and octahedral sites in a $\mathrm{Co}_{2} \mathrm{NiSe}_{4}$ crystal confirming that the sites are coordinatively unsaturated after synthesis. Once the sample was placed in the electrolyte, a shoulder peak started to emerge at $c a 2.0 \AA$ and a new peak at $c a .3 .0 \AA$ due to the oxidation of $\mathrm{Ni}$ and $\mathrm{Co}$ and backscattering of $\mathrm{Ni}-\mathrm{O} / \mathrm{Co}-\mathrm{O}$ and $\mathrm{Ni}-\mathrm{Ni} / \mathrm{Co}-\mathrm{Co}$ in the oxyhydroxides. In the case of $\mathrm{Co}$, there is an additional peak at $c a .3 .5 \AA$, a finding we assign to Co occupying an octahedral site in the starting spinel structure. ${ }^{[36]}$ The Ni-O peak was shifted to the left to $1.88 \AA$ during OER (at $1.5 \mathrm{~V}$ ) suggesting that Ni oxidized to $\gamma-\mathrm{NiOOH} .{ }^{[37]}$ The Co-O peak at $1.93 \AA$ after the OER confirms the formation of $\gamma$-CoOOH. ${ }^{[38]}$ These in situ observations agree with findings from ex situ EELS and sXAS analysis. Finally, XANES spectra were collected for the electrocatalyst after 400 hours of the OER. We found that Ni oxidation state reverted to $2+$ after the reaction while Co oxidation maintained a $3+$ oxidation state similar to during the OER (Figure S21). This indicated that, in contrast with the case of $\mathrm{Ni}$, Co oxidation from $2+$ to $3+$ is irreversible and that the electrocatalyst is stable after 400 hours of operation.

DFT calculations were used to help in explicating the experimental observations of Se leaching and of surface restructuring to an active oxide layer. Here, OER intermediates were 


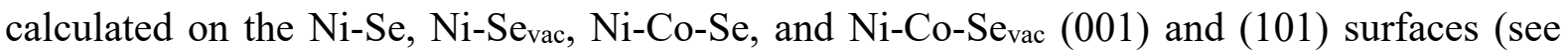

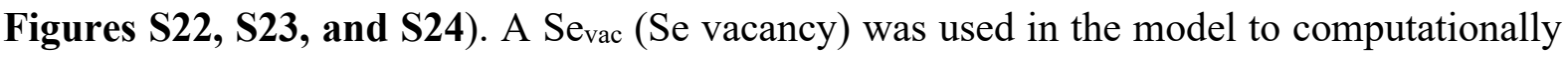

277 study the electronic effect of the vacancies, that are left behind in the structure due to Se removal by electrochemical activation, on neighbouring $\mathrm{Ni}$ and $\mathrm{Co}$ atoms.

Similar results were found for both Miller indices; this discussion shall therefore focus on (101) surfaces and the details of the (001) surface can be found in the Supporting Information. The formation of adsorbed $\mathrm{OOH}$ on $\mathrm{Ni}-\mathrm{Se}$ and $\mathrm{Ni}-\mathrm{Co}-\mathrm{Se}$ was the least enthalpically-favoured reaction step; so, we focus on the structural and electronic aspects for the adsorbed $\mathrm{O}$ and $\mathrm{OOH}$. Both Ni-Se and Ni-Co-Se (101) surfaces showed a short interatomic distance of approximately $1.7 \AA$ between a surface Se and the adsorbed O atom (see Table S7). The Bader charge analysis shows the Se atom adopted a positive charge as it transferred an electron to the adsorbed $\mathrm{O}$ atom (Figure S25). The changes to the Se atom's electronic structure closest to the adsorbed $\mathrm{O}$ atom on both Ni-Se and Ni-Co-Se (101) surfaces are also confirmed through their projected density of states (Figure S26). The Se-O bond formed suggests the possibility of $\mathrm{Se}$ leaching as $\mathrm{SeO}$ desorption rather than continuing the OER cycle to form adsorbed peroxide on the surface. A comparison between the two processes is justified because the formation of adsorbed $\mathrm{OOH}$ on $\mathrm{Ni}-\mathrm{Se}$ and $\mathrm{Ni}-\mathrm{Co}-\mathrm{Se}$ surfaces represents the potential rate determining step (Figure 5b). The enthalpies of both the $\mathrm{OOH}$ formation and $\mathrm{SeO}$ desorption were computed. As shown in Figure $\mathbf{5 b}$, while both processes are enthalpically competitive on the Ni-Se surface, the $\mathrm{SeO}$ desorption is not enthalpically favoured on the Ni-Co-Se surface. At a Ni site, the oxygen is also bonded to the nickel; therefore, SeO desorption would disrupt more surface interactions. At a Co site, the loss of a coordinating Se destabilizes the electron hole created by the dopant, Co. Se leaching is not enthalpically favoured over continuing the OER cycle, yet Se leaching has been observed experimentally, from which we propose that it is an entropically driven process. 
301 formed a bond with the adsorbed $\mathrm{O}$ atom on the $\mathrm{Ni}-\mathrm{Se}$ and $\mathrm{Ni}-\mathrm{Co}-\mathrm{Se}$ (101) surfaces, 302 respectively. OER intermediates were calculated again at the same adsorption sites to 303 demonstrate the effects of a Se vacancy. The potential energy differences associated with the 304 potential determining step do not decrease significantly with Co doping or a Se vacancy 305 separately (Figure 5c and S23). These surface modifications have the same effect on the Ni$\mathrm{O}$ distances for OER intermediates at a Ni site. The Ni-O distances for $\mathrm{OH}, \mathrm{O}, \mathrm{OOH}$, and $\mathrm{O}_{2}$ adsorbed on Ni-Se $\mathrm{vac}_{\text {ac }}$ and Ni-Co-Se are between 1.9 and $2.1 \AA$ which is much shorter than the $\mathrm{Ni}-\mathrm{O}$ distances on Ni-Se, which were all above $3 \AA$. The Ni-O distances for $\mathrm{H}_{2} \mathrm{O}$ on each (101) surface investigated were above $3 \AA$. The corresponding PDOS did not differ from those of the bare surfaces, and this indicates the water molecule does not interact strongly with the surface. Further discussion will be limited to the adsorbed $\mathrm{OH}, \mathrm{O}, \mathrm{OOH}$, and $\mathrm{O}_{2}$ species. Like the NiCo-Se (101) surface, the Ni-Se vac (101) surface also shows a bond forming between another surface Se and the adsorbed oxygen atom. The Se-O interatomic distance is approximately 1.8

$314 \AA$, and the Bader charge shows the Se transfer of an electron to the adsorbed O atom on Ni-

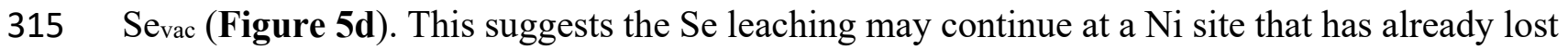
a Se atom, although it will be less enthalpically favoured than the first Se loss because both NiSe and Ni-O bonds will be disrupted.

The combination of Co-doping and a Se vacancy on the (101) surface behaves differently from the Ni-Se, Ni-Se vac, and Ni-Co-Se surfaces discussed above. The potential determining step becomes the oxygen molecule desorption. The significantly higher $\mathrm{O}_{2}$ desorption energy for the $\mathrm{Ni}-\mathrm{Co}-\mathrm{Se}_{\mathrm{vac}}(101)$ surface is due to the second oxygen atom also binding to two metal atoms. The desorption from this surface breaks three Ni-O bonds and one

323 Co-O bond, unlike Ni-Se, Ni-Se vac, Ni-Co-Se (101) surfaces where, at most, two metal-oxygen 324 bonds are broken. The greater number of bonds between surface metal atoms and adsorbed 
oxygen atoms combined with the high $\mathrm{O}_{2}$ desorption energy shows that, rather than lose $\mathrm{O}_{2}$ through desorption, the $\mathrm{Ni}-\mathrm{Co}-\mathrm{Se}_{\mathrm{vac}}$ surface forms an active oxide layer.

In addition to the energetic differences, several structural and electronic features distinguish the Ni-Co-Se $e_{\text {vac }}(101)$ surface from the $\mathrm{Ni}-\mathrm{Se}, \mathrm{Ni}-\mathrm{Co}-\mathrm{Se}$, and $\mathrm{Ni}-\mathrm{Se}$ vac surfaces. The metal-oxygen distances are shorter than those calculated on the Ni-Se, Ni-Co-Se, and Ni-Sevac surfaces. The Ni-O distances on Ni-Co-Sevac for $\mathrm{OH}, \mathrm{O}, \mathrm{OOH}$, and $\mathrm{O}_{2}$ are between 1.8 and 1.9 $\AA$, while the Co-O distances are between 1.7 and $1.9 \AA$ (Tables S7 and S9). The distances for the $\mathrm{Ni}$ and $\mathrm{Co}$ sites on $\mathrm{Ni}-\mathrm{Co}-\mathrm{Se}_{\mathrm{vac}}$ are consistent with $\gamma-\mathrm{NiOOH}^{[37]}$, and $\gamma-\mathrm{CoOOH}^{[38]}$ in agreement with the present EXAFS results and will cycle between these structures and their corresponding hydroxides throughout the OER. ${ }^{[39,40]}$ The distinction between a Ni and a Co site is lost on the Ni-Co-Sevac (101) surface due to the adsorbed oxygen species filling the Se vacancy and bridging a surface $\mathrm{Co}$ and $\mathrm{Ni}$ atom. The first adsorbed oxygen species replaces the desorbed Se atom to stabilize the electron hole created by the presence of Co. This simple substitution was not observed on $\mathrm{Ni}-\mathrm{Se}_{\mathrm{vac}}$ and implied the original structure might be more preserved in $\mathrm{Ni}-\mathrm{Co}-\mathrm{Se}_{\mathrm{vac}}$ as the surface oxidation progresses. The ratio of the Ni Bader charges for the $\mathrm{O}, \mathrm{OOH}$, and $\mathrm{O}_{2}$ intermediates on the Ni-Co-Se, Ni-Sevac, and Ni-Co-Sevac surfaces compared with the Ni Bader charge on the corresponding bare surfaces show the Ni has been oxidized from $\mathrm{Ni}^{+2}$ to $\mathrm{Ni}^{+3}$. The Ni-Co-Se vac surface differs from the other two surfaces, as a similar analysis shows the $\mathrm{Co}$ atom is also oxidized to $\mathrm{Co}^{+3}$. Furthermore, an electron transfer from a surface $\mathrm{Se}$ on $\mathrm{Ni}-\mathrm{Co}-\mathrm{Se}_{\mathrm{vac}}$ was only observed due to the secondary $\mathrm{O}$ atom in the $\mathrm{OOH}$ intermediate, otherwise, the Se Bader charges remained constant (Figure 5d). These electronic differences are confirmed through projected densities of states (Figure S27) and agree with the present EELS results.

Our DFT calculations have shown that Se leaching is not an enthalpically favoured process; so, it must be entropically driven. While the $\mathrm{Ni}-\mathrm{Co}-\mathrm{Se}, \mathrm{Ni}-\mathrm{Se} \mathrm{vac}_{\mathrm{c}}$, and $\mathrm{Ni}-\mathrm{Co}-\mathrm{Se}_{\mathrm{vac}}$ 
surface all showed the $\mathrm{Ni}$ atom becoming oxidized, the shortest metal-oxygen bonds and $\mathrm{Co}$ oxidation were only observed on the Ni-Co-Se $e_{\text {vac }}$ surface. A surface Se atom only transferred an electron to the second oxygen atom adsorbed on the Ni-Co-Se $e_{v a c}$ surface contributing to the high energy of the $\mathrm{O}_{2}$ desorption, thereby energetically favouring the surface restructuring to the active $\gamma-\mathrm{NiCoOOH}$. The Bader charge analysis and calculated structures agree with the present experimental results. The resulting active surface is therefore $\mathrm{NiCoOOH}$. The good OER activity observed experimentally is an agreement with a recent Shin et al. computational study ${ }^{[13]}$ which showed that $\gamma-\mathrm{NiOOH}$ doped with Co had the lowest theoretical overpotential, $270 \mathrm{mV}$, out of a range of transition metal dopants, including Fe. ${ }^{[41,42]}$ The study predicted that $\mathrm{Co}$ when doped with $\gamma-\mathrm{NiOOH}$ can help in the stabilization of the formation of $\mathrm{O}$ on the MO bond while the $\mathrm{O}-\mathrm{O}$ coupling is catalyzed on $\mathrm{Ni}$ active sites, making the catalyst a much better OER catalyst than $\gamma-\mathrm{NiOOH}$.

\subsection{AEM water and $\mathrm{CO}_{2} \mathrm{R}$ electrolyser}

To further evaluate the performance of activated $(\mathrm{NiCo})_{3} \mathrm{Se}_{4}(\mathrm{NiCoOOH})$ as an $\mathrm{OER}$ electrocatalyst for industrial water splitting and $\mathrm{CO}_{2} \mathrm{R}$, we used a $5 \mathrm{~cm}^{2} \mathrm{AEM}$ electrolyser with the cathodic reaction supported by $\mathrm{Pt} / \mathrm{C}$ on carbon paper for hydrogen evolution and $\mathrm{Cu}$ on PTFE for $\mathrm{CO}_{2} \mathrm{R}$ (Figures 6a and 6d). The polarization curves indicated that the catalyst lowered the cell voltage to $2 \mathrm{~V}$ at $2 \mathrm{~A}_{\mathrm{cm}} \mathrm{cm}^{-2}$ for water splitting (Figure $\mathbf{6 b}$ ) and $3 \mathrm{~V}$ at $1 \mathrm{~A} . \mathrm{cm}^{-2}$ for $\mathrm{CO}_{2} \mathrm{R}$ using $1 \mathrm{M} \mathrm{KOH}$, outperforming $\mathrm{IrO}_{2}$ (Figure 6e). This performance was stable for $95 \mathrm{~h}$ at $1 \mathrm{~A} . \mathrm{cm}^{-2}$ for water splitting (Figure 6c) and $5 \mathrm{~h}$ at $0.5 \mathrm{~A}^{-\mathrm{cm}^{-2}}$ for $\mathrm{CO}_{2} \mathrm{R}$ (Figure 6f). These results demonstrated the potential of utilizing cryomilled $(\mathrm{NiCo})_{3} \mathrm{Se}_{4}$ for industrial applications.

\section{Conclusions}

In summary, we reported in this work the synthesis of homogenously dispersed Ni-Co-

374 Se nanocrystals with varying compositions using solid-state cryomilling. Electrochemical 
375 leaching of Se from the structure facilitated the transformation to $\mathrm{Ni} / \mathrm{Co}$-oxyhydroxides as 376 validated by DFT, TEM, sXAS, and in situ XAS. The best performing activated (NiCo) ${ }_{3} \mathrm{Se}_{4}$

377 electrocatalyst showed a stable OER performance drawing 0.5 A.cm ${ }^{-2}$ at $279 \mathrm{mV}$, and 1 A.cm

$3782^{2}$ at $329 \mathrm{mV}$ of overpotential for 500 hours in $1 \mathrm{M} \mathrm{Fe}$-free $\mathrm{KOH}$. Integrating the electrocatalyst 379 in an AEM electrolyser, we could demonstrate an outstanding water splitting performance 380 delivering $2 \mathrm{~A} \cdot \mathrm{cm}^{-2}$ at $2 \mathrm{~V}$ and $\mathrm{CO}_{2} \mathrm{R}$ performance of $1 \mathrm{~A} \cdot \mathrm{cm}^{-2}$ at $3 \mathrm{~V}$. The results encourage 381 the utilization of cryomilling and chalcogenides, such as Se, to mass produce efficient earth382 abundant electrocatalysts with long-term durability.

\section{Acknowledgments}

385 This work was supported financially by the Natural Sciences and Engineering Research 386 Council (NSERC) of Canada, Vanier Canada Graduate Scholarship, and TOTAL SE. Electron microscopy, scanning transmission electron microscopy, and electron energy loss spectroscopy were performance at the Canadian Centre for Electron Microscopy (CCEM) at McMaster University. This research used resources of the Advanced Photon Source, an Office of Science User Facility operated for the U.S. Department of Energy (DOE) Office of Science by Argonne National Laboratory and was supported by the U.S. DOE under Contract No. DE-AC0206CH11357, and the Canadian Light Source and its funding partners. The authors thank Dr.

393 Tianpin Wu and Dr. George Sterbinsky from 9BM beamline, and Dr. Debora Motta Meira and Dr. Zou Finfrock from 20BM beamline for assistance in collecting the XAS data and at the advanced photo source (APS). DFT calculations were conducted as part of the Engineered Nickel Catalysts for Electrochemical Clean Energy project administered from Queen's University and supported by Grant No. RGPNM 477963-2015 under the Natural Sciences and Engineering Research Council of Canada (NSERC) Discovery Frontiers Program. The computational resources were provided by Compute Canada. 
400 Competing Interests Statement

401 The authors declare no competing interests

402 


\subsection{References}

[1] P. P. Sharma, X. D. Zhou, Wiley Interdiscip. Rev. Energy Environ. 2017, 6, DOI 10.1002/wene.239.

[2] P. De Luna, C. Hahn, D. Higgins, S. A. Jaffer, T. F. Jaramillo, E. H. Sargent, Science (80-. ). 2019, 364, DOI 10.1126/science.aav3506.

[3] C.-T. Dinh, G. Kibria, A. Seifitokaldani, A. Kiani, O. S. Bushuyev, C. Zou, R. Quintero-Bermudez, E. H. Sargent, T. Burdyny, C. M. Gabardo, J. P. Edwards, Y. Pang, D. Sinton, P. De Luna, Science (80-. ). 2018, 360, 783.

[4] J. R. SGalán-Mascarós, ChemElectroChem 2015, 2, 37.

[5] H. Zhou, F. Yu, Q. Zhu, J. Sun, F. Qin, L. Yu, J. Bao, Y. Yu, S. Chen, Z. Ren, Energy Environ. Sci. 2018, 11, 2858.

[6] M. Yu, G. Moon, E. Bill, H. Tüysüz, ACS Appl. Energy Mater. 2019, 2, 1199.

[7] M. Gong, Y. Li, H. Wang, Y. Liang, J. Z. Wu, J. Zhou, J. Wang, T. Regier, F. Wei, H. Dai, J. Am. Chem. Soc. 2013, 135, 8452.

[8] C. Liang, P. Zou, A. Nairan, Y. Zhang, J. Liu, K. Liu, S. Hu, F. Kang, H. J. Fan, C. Yang, Energy Environ. Sci. 2019, 13, DOI 10.1039/c9ee02388g.

[9] C. Kuai, Z. Xu, C. Xi, A. Hu, Z. Yang, Y. Zhang, C. Sun, L. Li, D. Sokaras, C. Dong, S. Qiao, X. Du, F. Lin, Nat. Catal. 2020, DOI 10.1038/s41929-020-0496-z.

[10] F. D. Speck, K. E. Dettelbach, R. S. Sherbo, D. A. Salvatore, A. Huang, C. P. Berlinguette, Chem 2017, 2, 590.

[11] D. Y. Chung, P. P. Lopes, P. Farinazzo Bergamo Dias Martins, H. He, T. Kawaguchi, P. Zapol, H. You, D. Tripkovic, D. Strmcnik, Y. Zhu, S. Seifert, S. Lee, V. R. Stamenkovic, N. M. Markovic, Nat. Energy 2020, 5, 222.

[12] M. Wang, Z. Dang, M. Prato, D. V. Shinde, L. De Trizio, L. Manna, ACS Appl. Nano Mater. 2018, acsanm.8b01418. 
428

429

430

431

432

433

434

435

436

437

438

439

440

441

442

443

444

445

446

447

448

449

450

451

452

[13] H. Shin, H. Xiao, W. A. Goddard, J. Am. Chem. Soc. 2018, 140, 6745.

[14] X. Fu, D. N. Beatty, G. G. Gaustad, G. Ceder, R. Roth, R. E. Kirchain, M. Bustamante, C. Babbitt, E. A. Olivetti, Environ. Sci. Technol. 2020, 54, 2985.

[15] W. Li, D. Xiong, X. Gao, L. Liu, Chem. Commun. 2019, 55, 8744.

[16] W. Li, X. Gao, D. Xiong, F. Wei, W. G. Song, J. Xu, L. Liu, Adv. Energy Mater. 2017, $7,1$.

[17] R. Gao, G. D. Li, J. Hu, Y. Wu, X. Lian, D. Wang, X. Zou, Catal. Sci. Technol. 2016, 6,8268 .

[18] M. Cui, C. Yang, B. Li, Q. Dong, M. Wu, S. Hwang, H. Xie, X. Wang, G. Wang, L. Hu, Adv. Energy Mater. 2021, 11, 1.

[19] L. Schultz, Mater. Sci. Eng. 1988, 97, 15.

[20] W. L. Johnson, Prog. Mater. Sci. 1986, 30, 81.

[21] K. B. Dhanalakshmi, S. Latha, S. Anandan, P. Maruthamuthu, Int. J. Hydrogen Energy 2001, 26, 669 .

[22] K. Fan, H. Zou, Y. Lu, H. Chen, F. Li, J. Liu, L. Sun, L. Tong, M. F. Toney, M. Sui, J. Yu, ACS Nano 2018, 12, 12369.

[23] C. Suryanarayana, Mechanical Alloying And Milling, CRC Press, 2004, 2004.

[24] D. Zheng, M. Li, Y. Li, C. Qin, Y. Wang, Z. Wang, Beilstein J. Nanotechnol. 2019, 9, 281.

[25] W. Shi, F. Guo, C. Zhu, H. Wang, H. Li, H. Huang, Y. Liu, Z. Kang, J. Mater. Chem. A 2017, 5, 19800 .

[26] B. Akabayov, C. J. Doonan, I. J. Pickering, G. N. George, I. Sagi, J. Synchrotron Radiat. 2005, 12, 392.

[27] Y. Liang, Y. Li, H. Wang, J. Zhou, J. Wang, T. Regier, H. Dai, Nat. Mater. 2011, 10, 780. 
477

[28] D. Meyers, S. Mukherjee, J. G. Cheng, S. Middey, J. S. Zhou, J. B. Goodenough, B. A. Gray, J. W. Freeland, T. Saha-Dasgupta, J. Chakhalian, Sci. Rep. 2013, 3, 3.

[29] M. Al Samarai, A. W. Hahn, A. Beheshti Askari, Y. T. Cui, K. Yamazoe, J. Miyawaki, Y. Harada, O. Rüdiger, S. Debeer, ACS Appl. Mater. Interfaces 2019, 11, 38595.

[30] C. Xiao, X. Lu, C. Zhao, Chem. Commun. 2014, 50, 10122.

[31] H. A. El-Sayed, A. Weiß, L. F. Olbrich, G. P. Putro, H. A. Gasteiger, J. Electrochem. Soc. 2019, 166, F458.

[32] B. G. Amin, A. T. Swesi, J. Masud, M. Nath, Chem. Commun. 2017, 53, 5412.

[33] P. F. Wang, Y. J. Guo, H. Duan, T. T. Zuo, E. Hu, K. Attenkofer, H. Li, X. S. Zhao, Y. X. Yin, X. Yu, Y. G. Guo, ACS Energy Lett. 2017, 2, 2715.

[34] B. Das, M. V Reddy, B. V. R. Chowdari, 2013, 1961.

[35] S. R. Mellsop, A. Gardiner, B. Johannessen, A. T. Marshall, Electrochim. Acta 2015, $168,356$.

[36] H. Y. Wang, Y. Y. Hsu, R. Chen, T. S. Chan, H. M. Chen, B. Liu, Adv. Energy Mater. 2015, 5,1 .

[37] D. Friebel, M. W. Louie, M. Bajdich, K. E. Sanwald, Y. Cai, M. Wise, M. Cheng, D. Sokaras, T. Weng, R. Alonso-mori, R. C. Davis, J. R. Bargar, J. K. Nørskov, A. Nilsson, A. T. Bell, J. Am. Chem. Soc 2015, 137, 1305.

[38] J. Huang, J. Chen, T. Yao, J. He, S. Jiang, Z. Sun, Q. Liu, W. Cheng, F. Hu, Y. Jiang, Z. Pan, S. Wei, Angew. Chemie - Int. Ed. 2015, 54, 8722.

[39] C. Marini, B. Joseph, S. Caramazza, F. Capitani, M. Bendele, I. Kantor, P. Lotti, O. Mathon, S. Pascarelli, P. Postorino, High Press. Res. 2017, 37, 1.

[40] D. Totir, Y. Mo, S. Kim, M. R. Antonio, D. A. Scherson, J. Electrochem. Soc. 2000, $147,4594$.

[41] J. Zaffran, M. C. Toroker, ChemistrySelect 2016, 1, 911. 
478 [42] F. Costanzo, Phys. Chem. Chem. Phys. 2016, 18, 7490.

479

480 
a

Step 1: Cryomilling

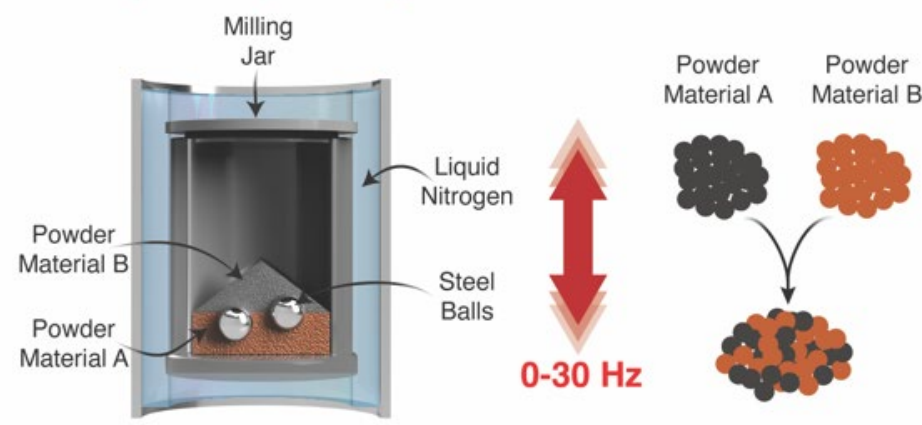

Step 2: Surfactant-Assisted Ball Milling (SABM)

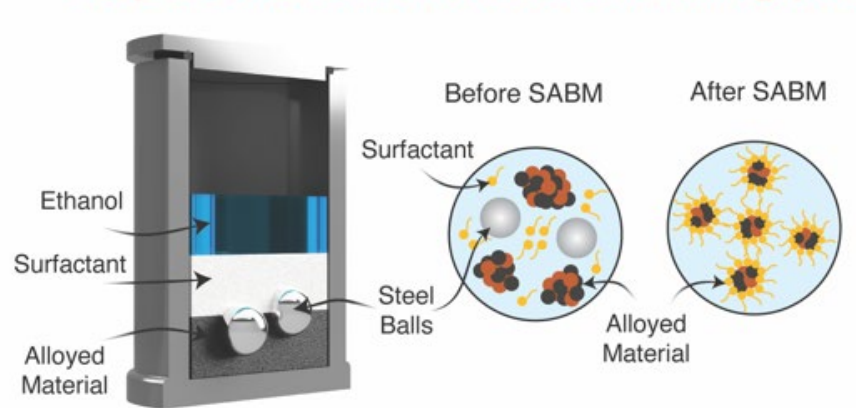

b

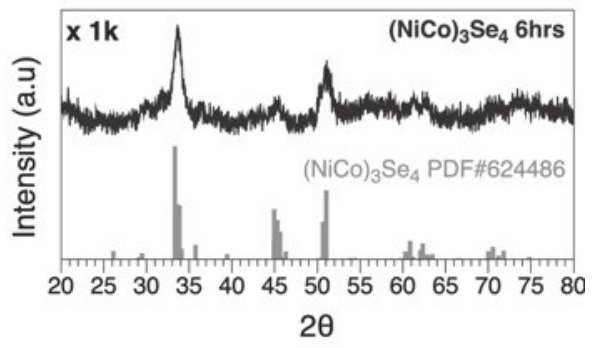

C

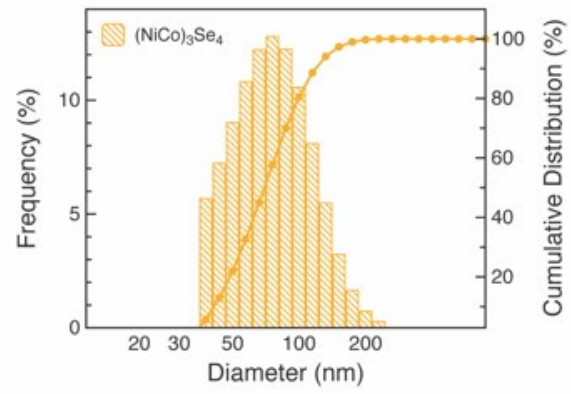

481

Figure 1. Schematic illustration of the two-step synthesis process a) step 1: milling at a cryogenic temperature $-196^{\circ} \mathrm{C}$ to alloy elements, step 2: milling in wet environment using

484 surfactant to reduce the size of the alloyed particles. b) XRD of (NiCo)Se and (NiCo) $)_{3} \mathrm{Se}_{4}$

485

486

487

488

489

490

491 
a

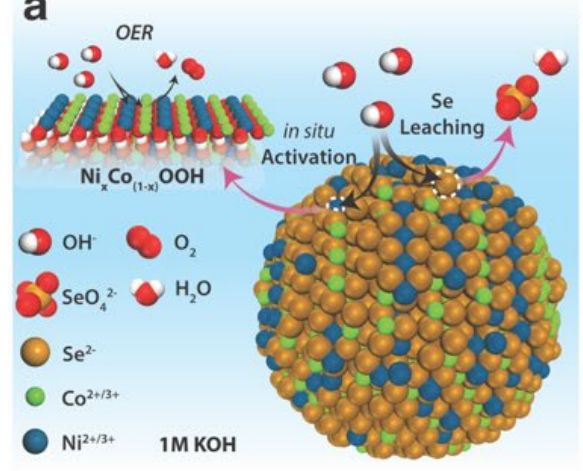

C
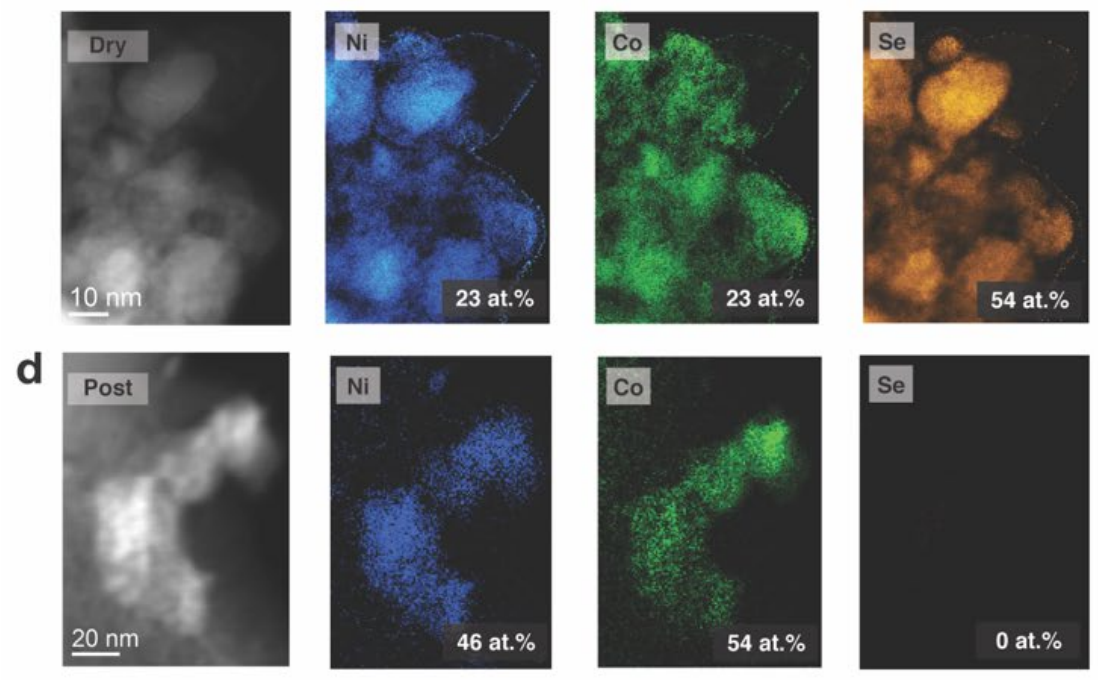

b
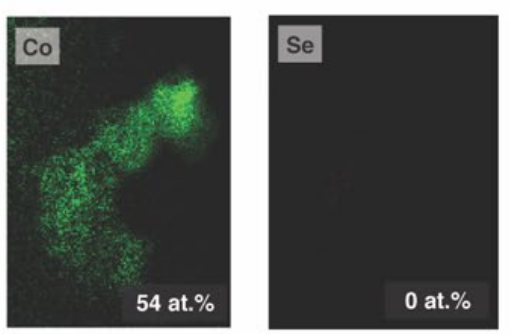
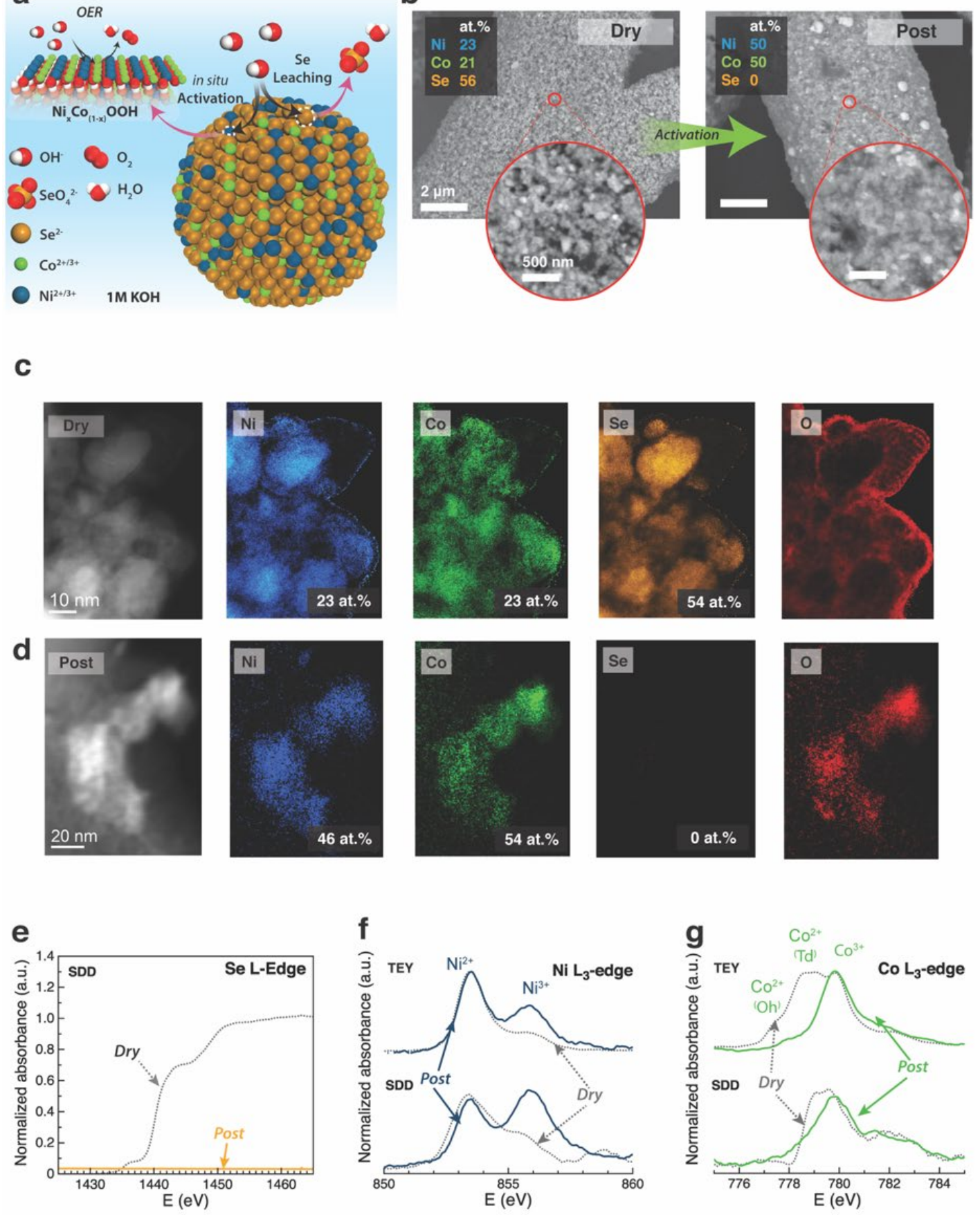

492

Figure 2. a) A schematic of the activation process for Ni-Co-Se alloys. b) BSE-SEM images and c) and d) TEM images of the (NiCo) ${ }_{3} \mathrm{Se}_{4}$ catalyst at $0 \mathrm{~h}$ (dry) and after $2 \mathrm{~h}$ of activation at $10 \mathrm{~mA} \cdot \mathrm{cm}^{-2}$ (post). The elemental content of the catalyst is shown in the inset tables. Soft X-ray L-edge XANES of e) Se using SDD, f) Ni and g) Co using TEY and SDD. 
a

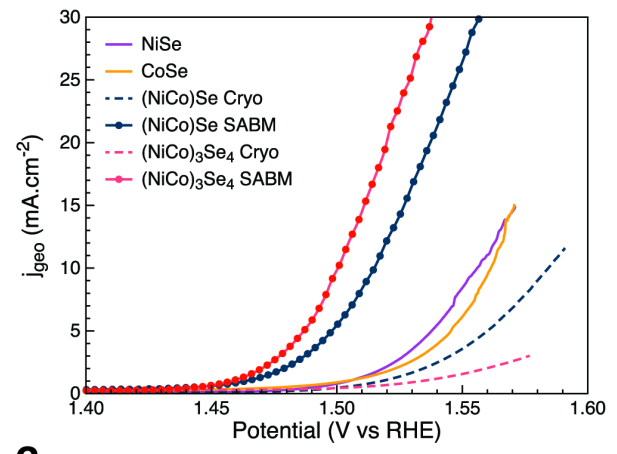

C

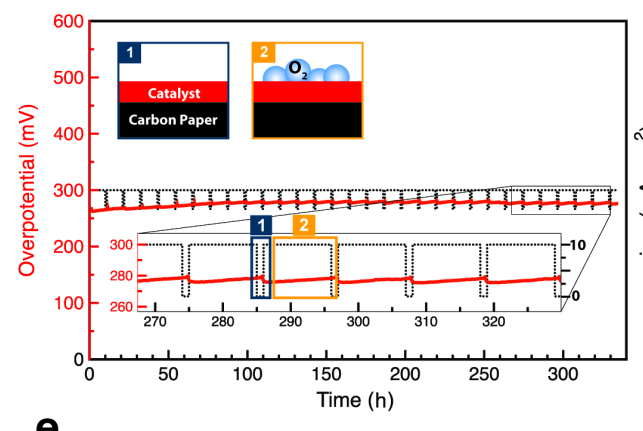

e

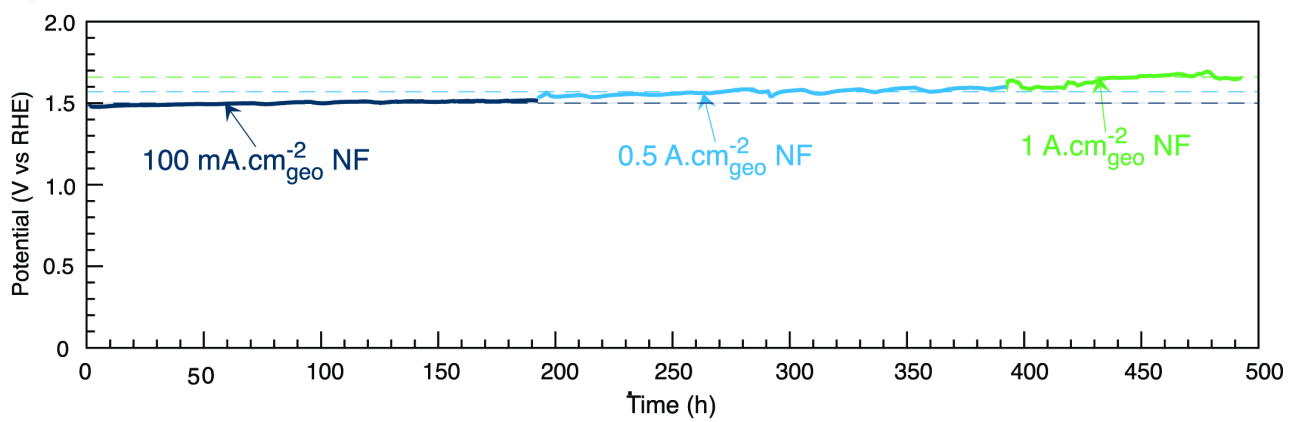

b

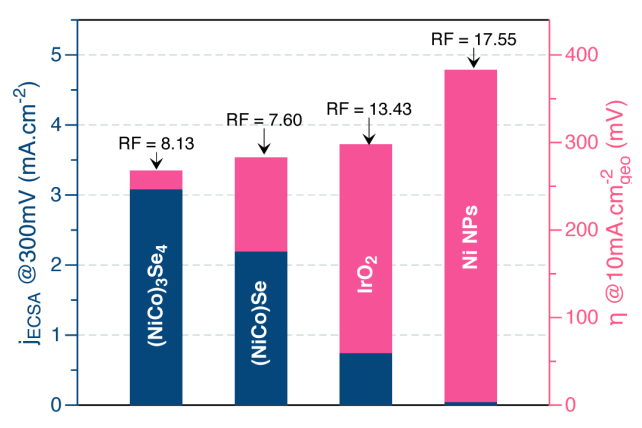

d

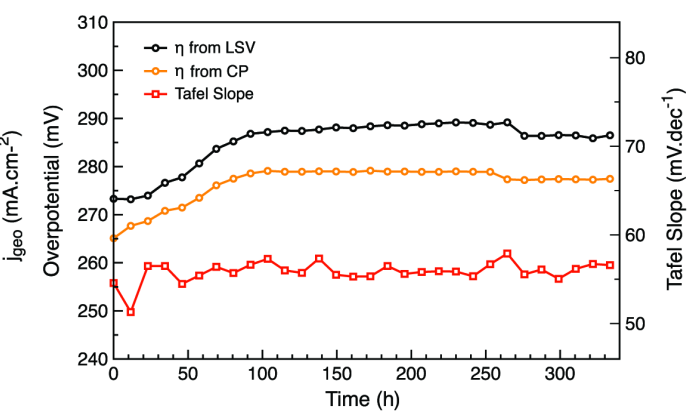

Figure 3. a) iR-corrected polarization curves on glassy carbon electrode with a loading of $0.21 \mathrm{mg} . \mathrm{cm}^{-2}$. b) Specific activity of activated $(\mathrm{NiCo})_{3} \mathrm{Se}_{4}$ and $(\mathrm{NiCo}) \mathrm{Se}$ compared to $\mathrm{IrO}_{2}$, normalized by ECSA at $300 \mathrm{mV}$ overpotential (left axis) and normalized by geometric area (right axis). The roughness factor (RF) value for each catalyst is noted at the top of the bar. c) Activated ( $\mathrm{NiCo})_{3} \mathrm{Se}_{4} \mathrm{NP}$ was deposited on carbon paper and tested using alternating stability test. Inset is a schematic illustration of $\mathrm{O}_{2}$ bubble accumulation on the surface of the electrocatalyst during oxidation. d) The change in key electrochemical parameters every 10 hours during the alternating stability test. e) Activated (NiCo) ${ }_{3} \mathrm{Se}_{4}$ was deposited on Nickel foam and tested for long term stability at high current densities. 
a

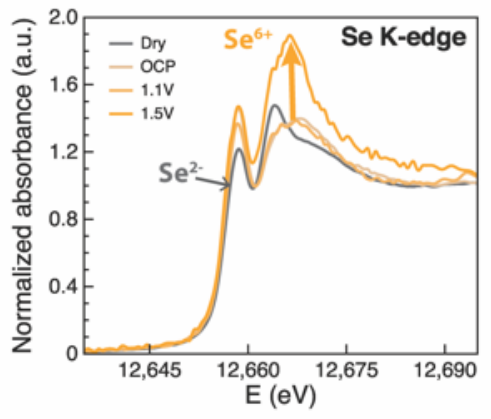

d

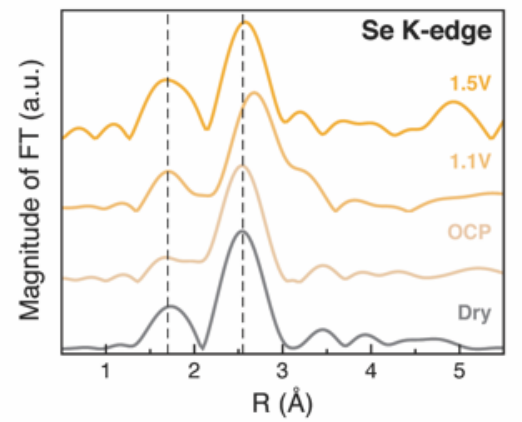

b

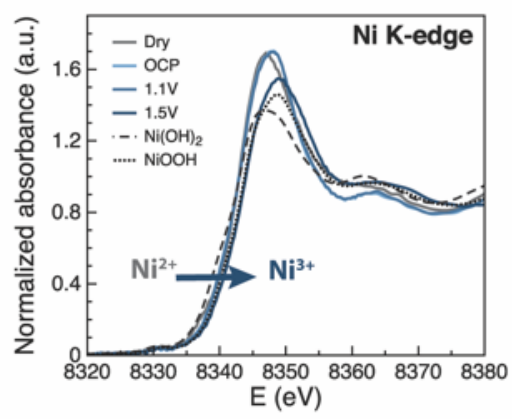

e

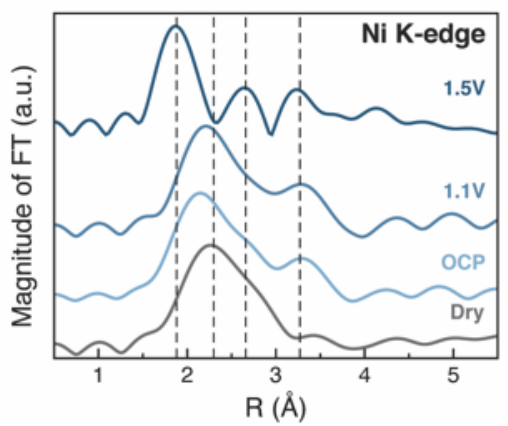

C

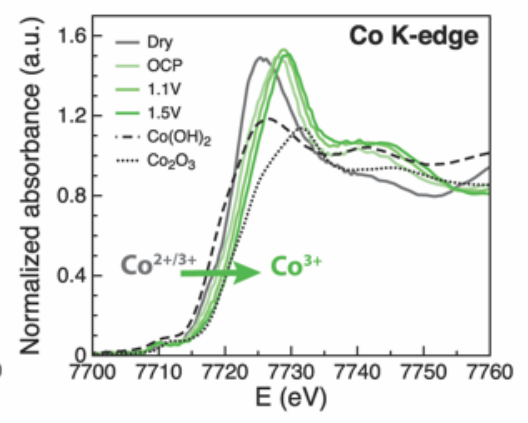

f

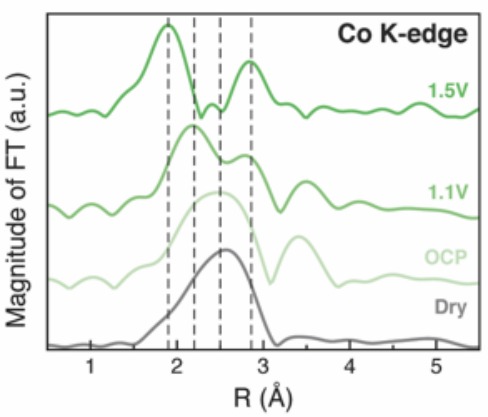

Figure 4. In situ XANES K-edge of a) $\mathrm{Se}, \mathrm{b}) \mathrm{Ni}$, and c) $\mathrm{Co}$ of (NiCo) ${ }_{3} \mathrm{Se}_{4}$ during OER. In

511 situ EXAFS radial distribution function of d) $\mathrm{Se}$, e) $\mathrm{Ni}$, and f) $\mathrm{Co}$ of $(\mathrm{NiCo})_{3} \mathrm{Se}_{4}$ during OER.

512 Interatomic distances noted in the figures are phase corrected using $0.5 \AA$ shift. All tests were 
a

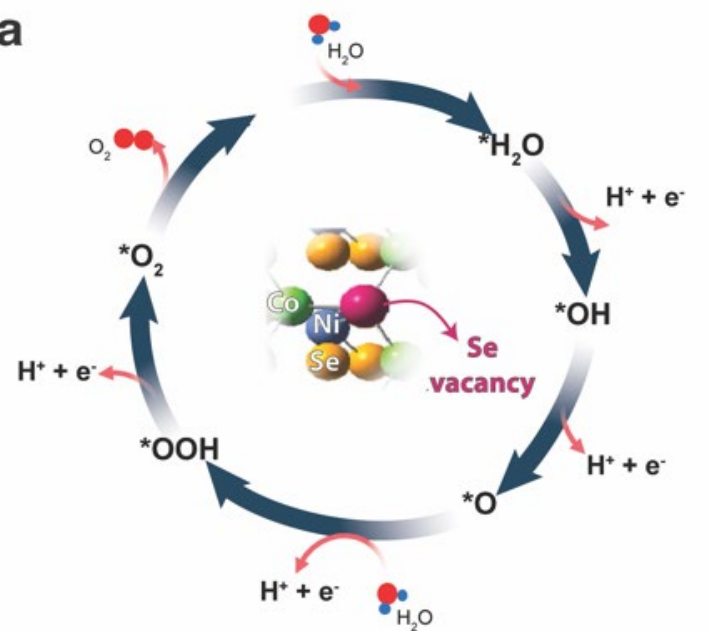

C

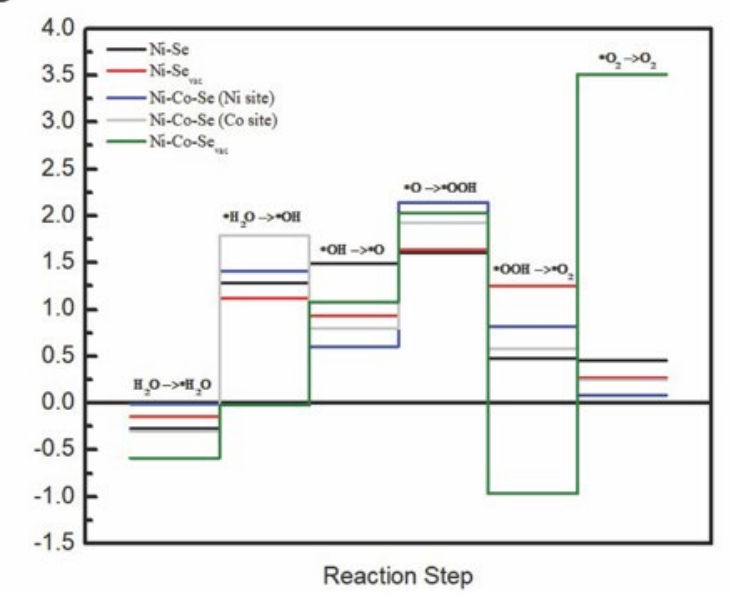

b
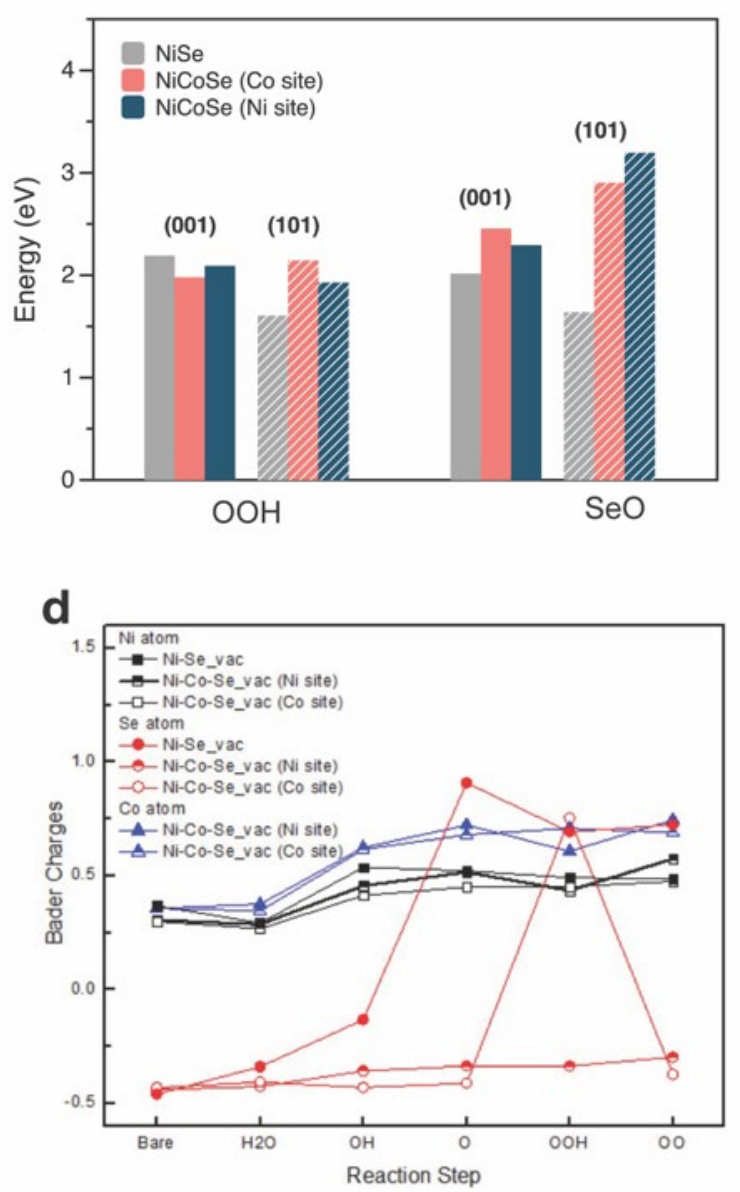

Figure 5. (a) OER mechanism on the NiSe (101) surface, the Se vacancy is highlighted in

517 magenta, Co doping sites are given in green, and $\mathrm{Ni}$ and $\mathrm{Se}$ are shown in blue and yellow,

518 respectively. (b) Comparing the energies of $\mathrm{OOH}$ formation and $\mathrm{SeO}$ desorption on (001) and

519 (101) surfaces. (c) The potential energy of reaction for Ni-Se, Ni-Sevac, Ni-Co-Se, and Ni-Co-

520 Sevac (101) surfaces (d) Bader charge of Ni, Se, and Co atoms for Ni-Se, Ni-Sevac, Ni-Co-Se

521 and Ni-Co-Sevac (101) surfaces.

522

523

524

525 
a AEM Water Electrolyser
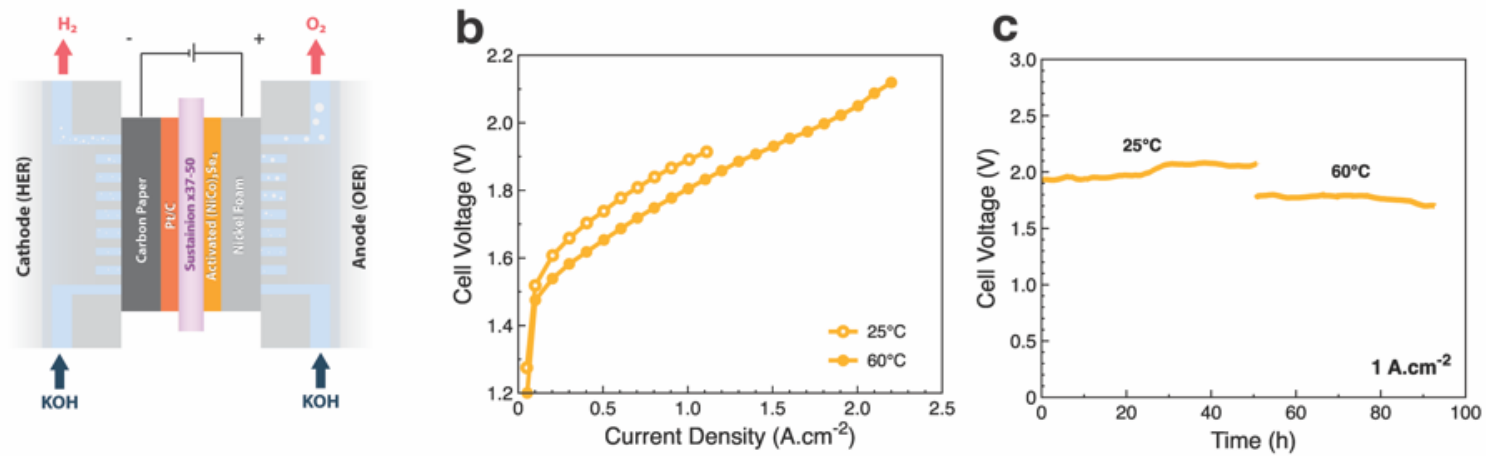

d $\mathrm{CO}_{2}$ Reduction

$\mathbf{e}$
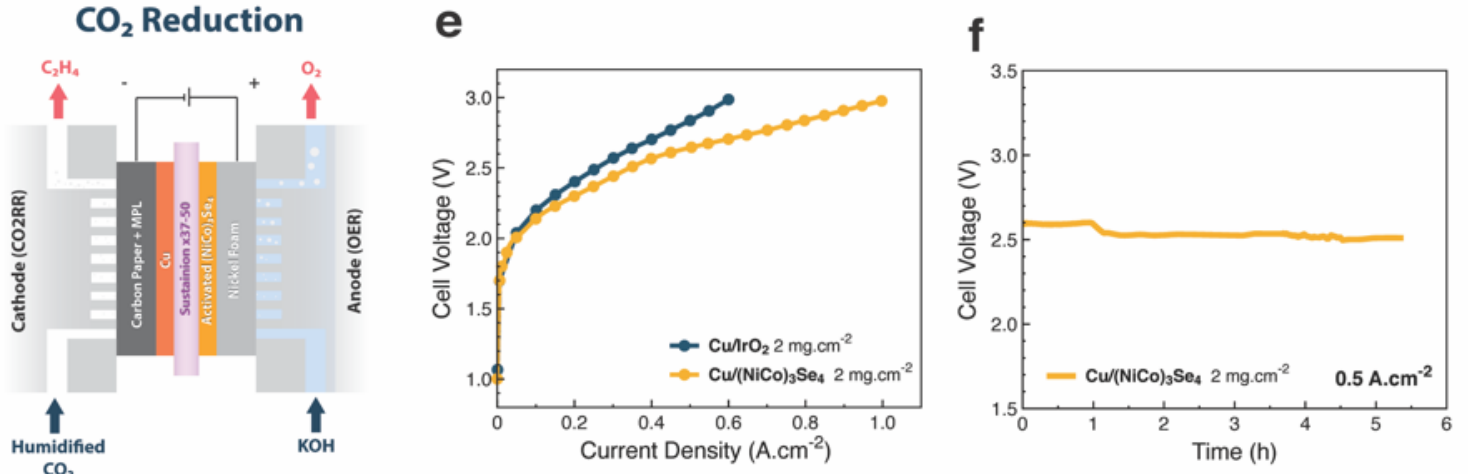

Figure 6. a) Schematic diagram of AEM water splitting b) Polarization curve and c)

528 Chronopotentiometry test using $0.2 \mathrm{mgPt} . \mathrm{cm}^{-2} \mathrm{Pt} / \mathrm{C}$ on carbon paper for HER and $2 \mathrm{mg} . \mathrm{cm}^{-2}$

529 Activated (NiCo) ${ }_{3} \mathrm{Se}_{4}$ on Nickel foam for OER. d) Schematic diagram of $\mathrm{CO} 2$ reduction. e)

530 Polarization curve and f) Chronopotentiometry test using $1 \mathrm{mg} . \mathrm{cm}^{-2} \mathrm{Cu}$ on PTFE for $\mathrm{CO}_{2} \mathrm{R}$

531 and $2 \mathrm{mg} . \mathrm{cm}^{-2}$ activated (NiCo) ${ }_{3} \mathrm{Se}_{4}$ on Nickel foam for OER compared to commercial $\mathrm{IrO}_{2}$.

532

533

534

535 